country will appreciate the cheery spirit in which, though consoious of grave organic disease, he brought his Presidential Address to a close with the words of Browning's " Rabbi Ben Ezra "-

"Grow old along with me;

The best is yet to be,

The last of life for which

The first was made.

Our times are in His hand

Who saith, 'A whole I planned.'

Youth shows but half; trust God,

Soo all, nor be afraid."

G. F. 8 .

\title{
DIETARY REPORT.
}

Copies of the Report of the Dietary Committee were sent to all the ordinary member (at the addresses given in the Journal for October, 1892) in July last. If any members has for any reason, not received his copy, it will be forwarded to him on application to Dr. Turnbull, Fife and Kinross District Asylum,
Cupar.

\section{NORSING CERTIFICATES.}

A list of the persons who obtained the Certificate of Proficienoy in Narsing at the Eraminations held in November, 1893 :-

MaLes. Framers.

City of Birmingham Asylum, Winson Green.

Jones, Amy Adelaide.

Jones, Georgina.

Keen, Selina

Truss, Alys.

Cordwell, Ebenezer.

County Asylum, Gloucester.

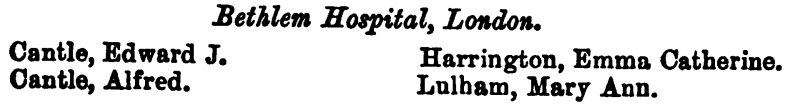

Bennott, John R.

County Asylum, Rainhill, Lancashire.

Eggo, Alexander.

Gore, Arthar.

Hazelhurst, John.

Hitchen, James.

Morgan, Henry.

Morton, Thomas.

Ross, James.

Smith, Albert.

Apencer, William Henry.

Smallshaw, James.

Stanton, James Layton.

Angus, Elizabeth.

Brotherton, Annie.

Bailey, Mary Ellen.

Cheese, Mary.

Day, Henrietta.

Dovey, Blanche Isabel.

Eastmond, Harriett I.

Freebury, Mary Ann.

Robinson, Caroline E. A.

Randel, May.

Turner, William Henry.

Watkinson, Evelyn. 


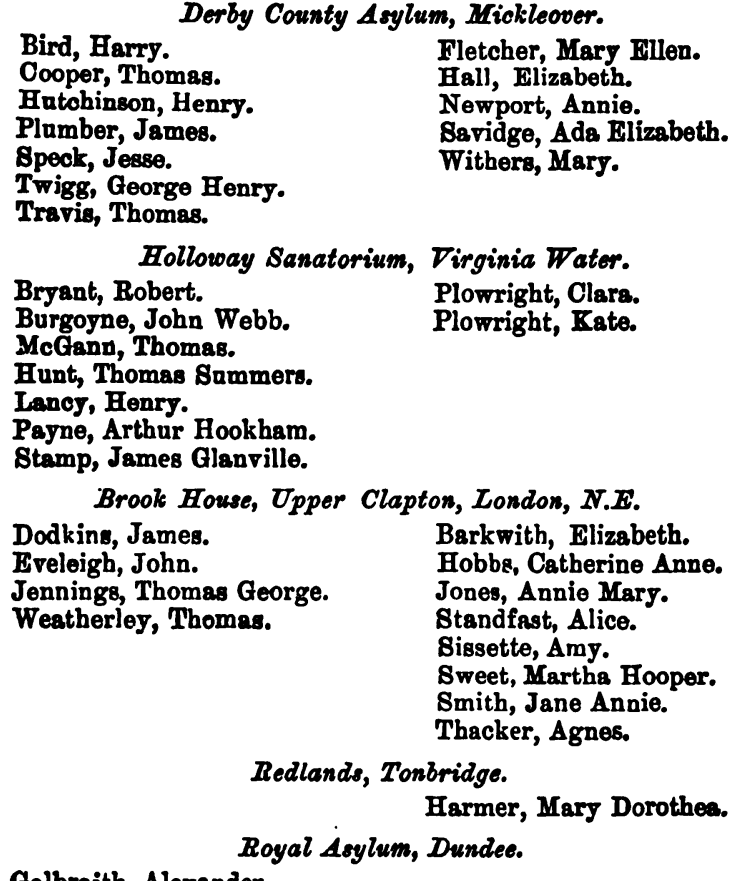

Galbraith, Alexander.

Soutar, Alexander.

By direction of the Council the name of Frederick Swadling was remored from the Register.

\section{QUESTIONS.}

1. What is the ordinary temperature of the body in health ? Is elevation of temperature frequent amongst the insane $P$. How wonld you proceed to ascertain exactly whether there was any rise of temperature in a given case?

2. A pationt has had a fall; what symptoms or conditions would lead you to suppose that one or more ribs had been broken ?

8. An epileptio patient has received a deeply incised wound of the scalp, which is bleeding freely; describe the steps you would take to arrest the bleeding and temporarily dress the wound.

4. What steps wonld you take to prevent the occurrence of bed sores in an enfeebled patient confined to bed? State the parts of the body to which you would pay special attention.

B. What indications in a patient's condition would lead you to suppose that in. sufficient nutriment was being taken, and that special attention to alimen. tation was necessary?

6. Describe generally the mental and bodily states of a patient suffering from Aoute Melancholia, and how would you act towards such a caes if you were placed in special charge? 
7. Give the anatomical names of the following bones:-(a) Collar bone, (b) Shoulder blade, (c) Thigh bone, (d) Bones of arm, (e) Bones of leg.

8. What weight and form of bed-clothing would you consider sufficient for patients in cold weather?

9. Amongst what class of insnne ratients is the suicidal impulse most likely to ocour?

10. The following articler of dietary are required for a patient :- (a) Beef tea, (b) Arrowroot, (c) Egg flip, (d) Castard padding. How would you prepare them?

11. A patient has swallowerl poicon; what means are you acquainted with for emptying the sumach? Give names and doses of some simple emetics.

12. What class of patients require special attention at meals, and what preoautions should be observed as to the character of their feod ?

Three hours allowed to answer this paper.

The questions are valued at 10 marks coch; two-thirds of the possible total of marks are required to pass.

\section{P. C. examination.}

Candidates who passed the Examination for the Certificate in England, in December, 1893 :-

J. Vincent Blachford, M.B., L.R.C.P.

Everitt E. Norton, M.R.C.S., L.R.C.P.

NOTICE OF QUARTERLY MEETING.

The next Quarterly Meeting of the Association will be held at Oxford, on Thursday, the 15th day of February, 1894, at 4 o'clock.

The adjourned Annual Meeting, to consider the Revised Rules, will meet on the same day at $10 \mathrm{am}$. The usual circular will give full particulars.

11, Chandos Street, Cavendish'Square, W., Fetererer Beach, Decomber 18, 1893.

Hon. Secretary.

\section{Appointments.}

BubB, WILliax, M.R.C.S., L.R.C.P.Lond, appointed Third Assistant Medical Officer to the Worcester Connty and City Lunatic Asylums.

Buagr, Lov1s, L.R.C.S.I., L. \& L.M., K.Q.C.P.I., appointed Assistant Medical Officer to the Kilkenny District Lunatic Asylum.

CrUxP, J. ArTHUr, L.R.C.P.Lond, M.R.C.S., appointed Assistant Medical Officer to the Wye House Asylum, Buxton.

Dovgras, ARCHIBaLd RoBErTBON, L.R.C.P., L.R.C.S.Edin., M.P.C., appointed Assistant Kesident Medical Officer at the Royal Albert Asylum, Lancaster.

Duncan, J. D., M.B., C.M.Edin., appointed Junior Medical Assistant to the Connties Asylum, Carlisle.

MACLARRN, JoHN, M.B., O.M.Edin., appointed Assistant Medical Officer to the East Riding Asylum, Beverley.

Nolan, Michare J., L.R.C.P., L.R.C.S.I., appointed Medical Superintendent of the Downpatrick Lunatio Asylum.

Sxitr, TrL Ford, B.A., M.D., M.Ch., appointed Medical Superintendent to the Royal Albert Asylum for Idiots and Imbeciles of the Northern Counties, Lancaster.

Watron, R. H., M.A., M.B., C.M., appointed Assislant Physician to the Inverness District Asylum. 